\title{
The impacts of introducing carbon prices in the electricity market under China's carbon neutrality goal
}

\author{
Runze Liu ${ }^{1, *}$, Zhaoxia Jing ${ }^{1}$ \\ ${ }^{1}$ School of Electric Power Engineering, South China University of Technology, Guangzhou 510640, Guangdong Province, China
}

\begin{abstract}
The world's energy system is undergoing an evolution from high-carbon to low-carbon. The Chinese government has also proposed the carbon neutral plan. Foreign practical experience shows that there is an interaction between the carbon market and the electricity market, therefore, understanding the relationship between the two markets is essential to ensure the efficient operation of both markets. In the context of China's power market reform, this paper studies the impact of introducing carbon prices into the wholesale market, and conducts a case study based on the data of a certain area in GD province. The results show that after the carbon price is transmitted to the electricity price, the more low-carbon and environmentally friendly power generation technologies will gain greater advantages in the electricity market, which is conducive to the clean energy transformation of the power system. Finally, this paper puts forward feasible suggestions for the reform of the electricity market under China's carbon emission reduction target.
\end{abstract}

\section{Introduction}

The climate issue is the most severe non-traditional security issue in the world today. Therefore, countries around the world have instituted strong policies to achieve decarbonization, and China is no exception. In 2020, president Xi proposed the "3060 Plan Timeline" for carbon neutrality, that is, China's carbon dioxide emission level will strive to reach its peak by 2030, and strive to achieve "carbon neutrality" by 2060. In China, the energy industry, as the largest carbon emission sector, is an important way to achieve carbon neutrality. In February 2021, the "Administrative Measures for Carbon Emission Trading (Trial)" was implemented on a trial basis, the national carbon market of China was launched simultaneously, which is the world's largest power industry carbon market.

There is an interaction between the electricity market and the carbon market ${ }^{[1,2]}$. On the one hand, the electricity market may have an impact on the efficiency of the carbon market ${ }^{[3]}$, such as generators' compensation and market supervision policies. A well-designed electricity market enables the price reflect the true cost of electricity production (including carbon costs), which helps reduce carbon emissions. On the other hand, carbon prices can be transmitted to electricity market prices. The carbon market will affect the revenue of generators, influencing investment decisions on low-carbon assets such as renewable energy facilities. Literature [4] analyzes the short-term impact of carbon prices on the US electricity market, confirming that carbon taxes can quickly reduce emissions in the power industry. Literature [5] further proposes that higher carbon prices make coal-fired power plants less competitive than natural gas power plants, further triggering the clean development of power generation investment portfolios.

Therefore, the separate design of electricity market policy and carbon market policy will lead to non-optimal social welfare and reduce the efficiency of the two markets. The power industry is an important part of energy and environmental policies, so the scheme of carbon market and power market must be combined. Exploring the integration mechanism of the electricity market and the carbon market will help the market operate efficiently and achieve the goal of carbon reduction at the lowest cost.

In terms of international practice, some countries and regions have begun to introduce carbon prices in the electricity market. In Europe, the carbon market has a very important impact on the electricity market. John Dearing ${ }^{[6]}$ confirmed that carbon prices will change the marginal cost of fossil fuel power stations, thereby promoting the low-carbon transformation of the energy system. P Aatola $^{[7]}$ established an econometric model and found that under the carbon emissions trading mechanism, the carbon price has a positive impact on the price of the integrated European electricity market. In December 2018, the New York Integrating Public Policy Task Force (IPPTF) put forward a proposal to introduce carbon prices into wholesale market prices. In October 2020, the Federal Energy Regulatory Commission (FERC) issued a policy, claimed that referring to European practices, it is encouraged to incorporate state carbon pricing policies into the wholesale electricity market in the US.

This article first analyzes China's existing carbon quota mechanism, and then establishes an interaction model between carbon prices and the electricity market. Then a case study is carried out based on the data from a

\footnotetext{
${ }^{\text {*}}$ Corresponding author: runze_liu@foxmail.com
} 
certain area of GD province in China. The results show that the wholesale market can provide price signals for green development of generators and encourage them to save energy and reduce emissions, and ultimately benefit the power industry's carbon reduction goals.

\section{The carbon market policy in China}

China has been conducting pilot carbon market since 2011 in several regions including Beijing, Tianjin, Shanghai, Chongqing, Hubei, Guangdong and Shenzhen, which has accumulated a lot of experience about market construction and operation. In 2016, the pilot carbon market in Fujian province was launched. In 2017, the "National Carbon Emission Trading Market Construction Plan (Power Generation Industry)" was released by the government, and the construction of carbon markets across China was launched.

As of December 31, 2020, the pilot carbon market in China had accumulatively traded 331 million tons of carbon dioxide, with a turnover of 7.336 billion yuan, covering nearly 3,000 companies in more than 20 industries including steel, power, and cement, of which electricity is the main industry. The national carbon market is officially launched in February 2021. Under the goal of carbon peak and carbon neutrality, during the "14th Five-Year Plan" period, the national carbon market in China will develop in leaps and bounds and the market mechanism will be further improved.

The most important part of introducing carbon prices into the electricity market is carbon pricing, that is, to measure the value of carbon emissions and pass it on to emitters. At present, the mainstream carbon pricing has two methods: emissions trading system ${ }^{[8]}$ (ETS) and carbon taxation ${ }^{[9]}$. The ETS establishes the supplydemand relationship of emission allowances and uses a market-based mechanism to determine the price of greenhouse gas emissions. Under this mode, generators purchase or sell carbon emission rights. Unlike the ETS, carbon tax is a non-market-oriented way. The government determines the carbon price and collects it directly through taxation.

The advantage of a carbon tax is to provide certainty for the prices of relevant entities, but the disadvantage is that the total amount of emission reduction cannot be determined $^{[10]}$. Under the ETS mechanism, although the emission price is relatively volatile, the total emission reductions can be controlled, which is conducive to achieving orderly and controllable emission reductions and low-carbon transitions. In addition, low-emission companies can profit by selling carbon emission allowances, while high-emission companies have to purchase carbon allowances to achieve emission reduction targets, which is more conducive to stimulating the enthusiasm of enterprises to reduce emissions.

China now adopts the ETS mechanism. The trading product of the national carbon market is carbon emission allowances. The total national carbon emissions are set by the government each year and the quota is reduced year by year, so as to achieve the carbon emission reduction target. Carbon emission credits are converted into carbon allowances for trading in accordance with pre-determined rules. Every market participant has a prescribed carbon quota, and the company's annual carbon emissions cannot exceed this quota. If the company uses technological means to reduce carbon emissions, it can sell the remaining quota in the ETS; if it exceeds the carbon quota, the shortfall must be purchased through the market, otherwise it will accept severe fines set by the government. Under the background of China's electricity market reform, the interaction between carbon market and electricity market is shown in Figure 1.

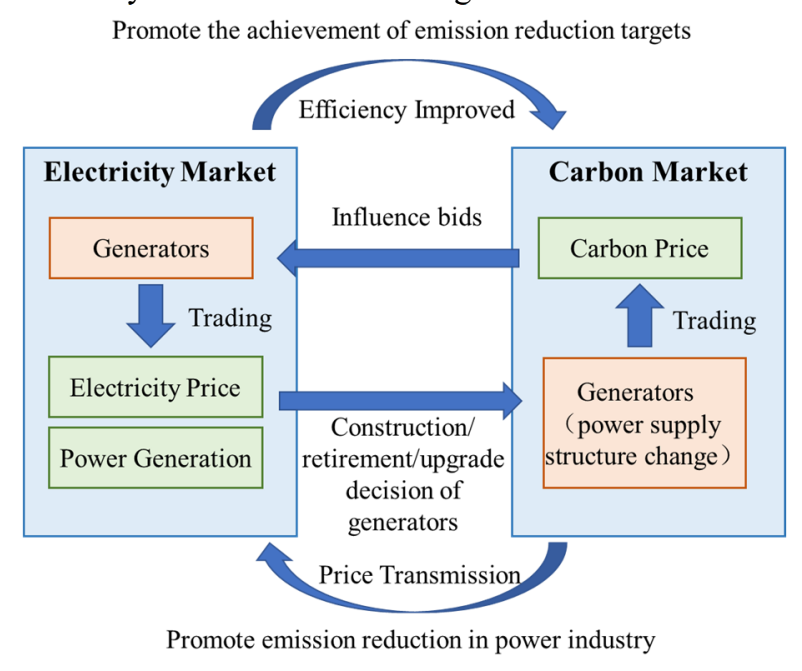

Fig. 1. Interaction Between Carbon Market and Electricity Market

\section{Model}

The model considers the electricity market and the carbon market, where the price of the carbon market will be transmitted to the generator quotations in the electricity wholesale market, affecting the types of clearing entities, the clearing volume, and the clearing price in the electricity market.

\subsection{Electricity market model}

\subsubsection{Objective function}

The objective function is to minimize the total cost of power generation. For the sake of simplicity, the reserve cost is not considered.

$$
\min \sum_{i=1}^{T} \sum_{i=1}^{I} C_{i}\left(p_{i, t}\right)
$$

Where $c_{i}\left(p_{i, t}\right)$ represents the operating cost of the generator $i$ in the period $t$ when its power output is $p . T$ is the time set of the optimization cycle, and $I$ is the set of generators.

Assume that each generator bids rationally (based on the marginal cost). In the electricity market, power suppliers add their additional carbon costs as a new part of their energy quotations $(\$ / \mathrm{MWh})$. As a result, the electricity market and the carbon market are linked to each other. 
The total marginal cost $C_{i}$ of generators include operation and maintenance $\operatorname{costs} C_{i}^{\mathrm{O} \& \mathrm{M}}$, fuel costs $H_{i} \cdot P_{i}^{\text {fuel }}$, and carbon costs $H_{i} \cdot Q_{i}^{\text {carbon }} \cdot P^{\text {carbon }}$ :

$$
C_{i}=C_{i}^{\mathrm{O \& M}}+H_{i} \cdot P_{i}^{\text {fuel }}+H_{i} \cdot Q_{i}^{\text {carbon }} \cdot P_{t}^{\text {carbon }}
$$

Where $H_{i}$ is the heat rate of generator $i, P_{i}^{\text {fuel }}$ is the fuel price of generator $i, Q_{i}^{\text {carbon }}$ is the carbon content ( $\left.\mathrm{CO}_{2} / \mathrm{btu}\right), P_{t}^{\text {carbon }}$ is the carbon price.

\subsubsection{Power balance constraint}

$$
\sum_{i \in I} p_{i, t}=\sum_{j \in D} L_{j, t}
$$

Where $L_{j, t}$ represents the load of the system in time period $\mathrm{t}$; $D$ is the load set of the electricity system.

\subsubsection{Constraints of generators}

Generators should meet the upper and lower power limits:

$$
y_{i, t} \cdot P_{i}^{\min } \leq p_{i, t} \leq y_{i, t} \cdot P_{i}^{\max }
$$

Where $P_{i}^{\max }$ and $P_{i}^{\min }$ are the upper and lower limits of unit output respectively. $y_{i, t}$ is the $0-1$ variable of the unit state, 0 represents the offline shutdown state, and 1 represents the online operation state.

\subsubsection{Network constraints}

The power flow constraints of transmission lines are as follows:

$$
-P_{l}^{\max } \leq p_{l, t} \leq P_{l}^{\max }
$$

Where $p_{l, t}$ is the power flow of line $l ; P_{l}^{\max }$ is the power flow constraint of line $l$.

\subsection{Carbon pricing model}

As mentioned in Section 2, there are two main approaches of carbon pricing: ETS and carbon tax. This paper is focused on China, in which the existing carbon policy is belong to the former mode. The volatility of carbon prices in the carbon market is relatively large, which is related to weather factors, fuel prices and other factors:

$$
P_{t}^{\text {carbon }}=f\left(R_{t}^{\mathrm{G} / \mathrm{C}}\right)+g\left(X_{t}\right)+Z_{t} \psi+D_{t} \gamma+\grave{o}_{t}
$$

Where $f$ and $g$ are part of the carbon price function, $R_{t}^{\mathrm{G} / \mathrm{C}}$ is the ratio of coal prices to natural gas prices. $X_{t}$ indicates variables that directly affect carbon emissions, including load, wind power, solar power, hydropower and other non-fossil fuel power generations. $Z_{t}$ indicates the intraday distribution of hourly load. $D_{t}$ is statistics on each quarter in the time series to reflect factors such as the available power generation capacity of the system and macroeconomic conditions in each quarter.

\section{Case study}

This paper sets the data of a certain city in GD province and scales them proportionally. The capacity limits of coal-fired or gas-fired power plants are determined based on the actual installed capacity of that area, and input variables such as fuel cost and heat rate use their actual data. The capacity limits for wind and solar energy are determined based on the most recent average monthly power generation level in that area. At present, hydropower plants in GD province are basically dispatched by the dispatching agency, and they do not have the power to make their daily generation schedules. Therefore, this article also determines the power generation capacity limit of hydropower plants based on the recent monthly average power generation. The load fluctuates by adding random numbers on the basis of the typical daily load curve of GD province. In addition,

\begin{tabular}{|c|c|c|c|c|}
\hline Number & Type & $\begin{array}{c}\text { Capacity } \\
\text { Limit } \\
\text { MW }\end{array}$ & $\begin{array}{l}\text { Carbon } \\
\text { Emission } \\
\text { lb/MWh }\end{array}$ & $\begin{array}{c}\text { Fuel } \\
\text { Cost } \\
¥ / \text { MWh }\end{array}$ \\
\hline 1 & \multirow{3}{*}{$\begin{array}{c}\text { Thermal } \\
\text { power }\end{array}$} & 200 & 1550.5 & 217 \\
\hline 2 & & 200 & 1322.7 & 220 \\
\hline 3 & & 200 & 1623.6 & 210 \\
\hline 4 & \multirow{2}{*}{$\begin{array}{c}\text { Gas } \\
\text { power }\end{array}$} & 150 & 470.1 & 230 \\
\hline 5 & & 150 & 210.8 & 245 \\
\hline 6 & $\begin{array}{l}\text { Hydro } \\
\text { power }\end{array}$ & 450 & 0 & 150 \\
\hline 7 & \multirow{2}{*}{$\begin{array}{l}\text { Wind } \\
\text { power }\end{array}$} & 50 & 0 & 0 \\
\hline 8 & & 50 & 0 & 0 \\
\hline 9 & \multirow{2}{*}{$\begin{array}{l}\text { Solar } \\
\text { power }\end{array}$} & 20 & 0 & 0 \\
\hline 10 & & 25 & 0 & 0 \\
\hline
\end{tabular}
weather factors such as temperature and gas prices all come from recent public data from GD Province. Part of the data of each type of unit is shown in Table 1.

Table 1. Data of each type of generators

The results of various power generation types are shown in Figure 2. It can be seen that although the cost of coal-fired power plants is higher than that of gas-fired power plants when only considering marginal costs of operation and maintenance and fuels (the original practice of power markets), after adding the cost of carbon emissions in the electricity market, since the carbon emissions per MW of coal-fired power plants are higher than that of gas-fired power plants, the calculated price of carbon emissions per MW is also higher, resulting in a decline in the competitiveness of coal power.

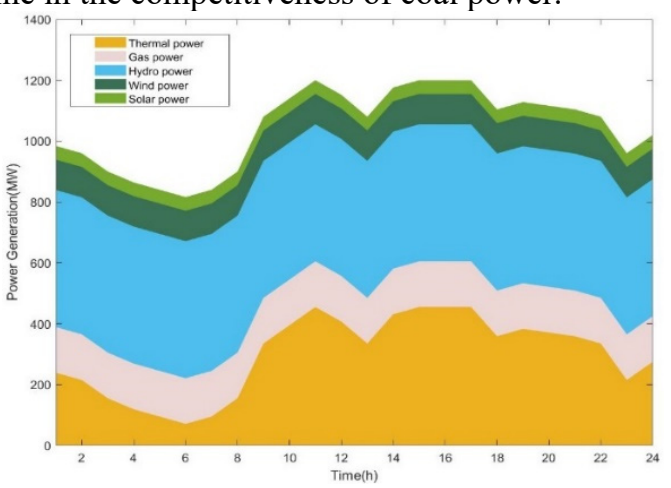

Fig. 2. Power Generation of Various Units 
To further verify the impact of carbon market prices on electricity market prices, three scenarios with different carbon price levels were set up. The carbon price in scenario 1 is 30 yuan/ton, the negotiation price in scenario 2 is 10 yuan/ton, scenario 3 is the control group, and the carbon price is 0 yuan/ton, indicates that the electricity market price and the carbon market price are not linked.

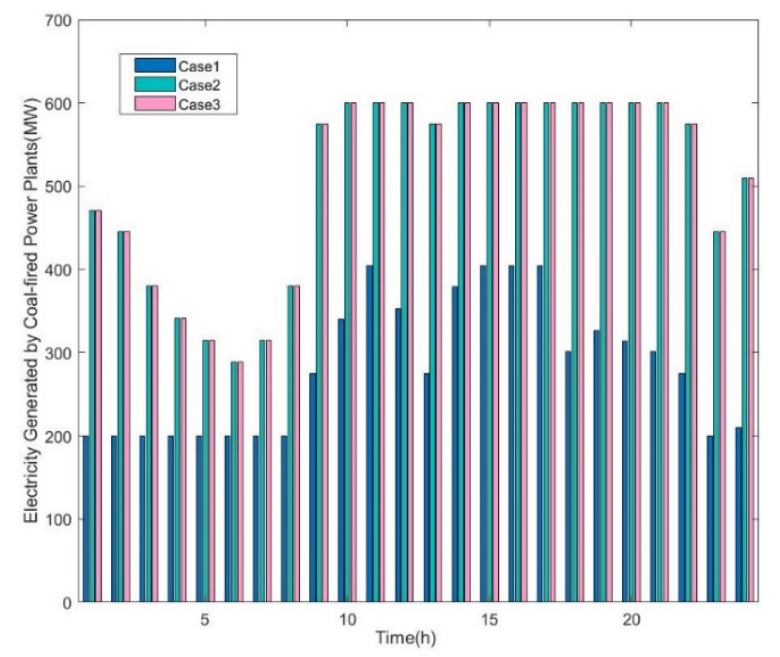

Fig. 3. Power Generation of Coal-fired power Plants Under Different Scenarios

Under three scenarios, the total power generation of coal-fired power plants in each period is shown in Figure 3 , and the total power generation of gas-fired power plants is shown in Figure 4.

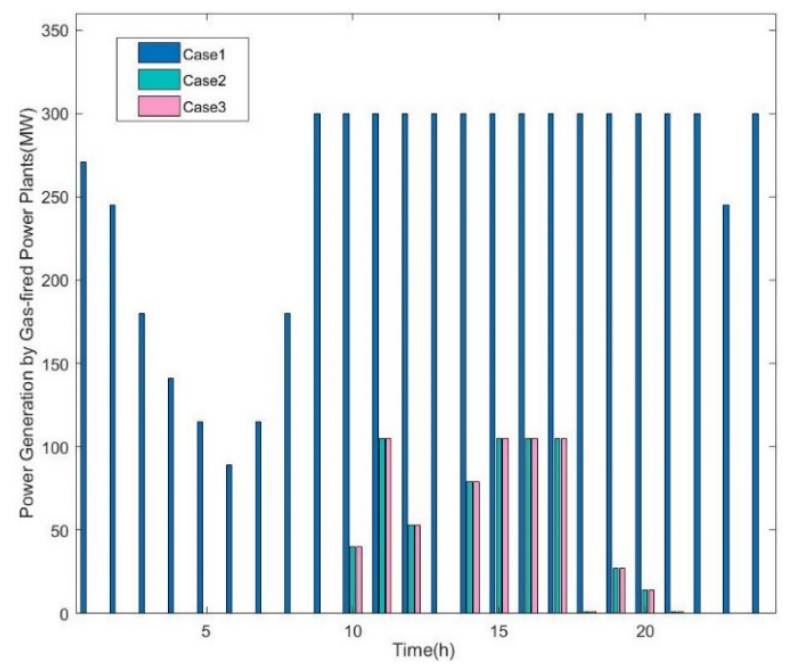

Fig. 4. Power Generation of Gas-fired power Plants Under Different Scenarios

It can be seen that under the load level set in this article, the power generation of coal-fired units will be significantly reduced when the carbon price is high, and in certain periods it can be less than half of that when the carbon price is not introduced (especially hour $0,1,22,23$, 24). The situation of gas generators is the opposite. Before the introduction of carbon prices in the electricity market, gas generators produced very little electricity, which were used as peak load generators to generate electricity at peak times (hour 10-12, 14-20). After the carbon prices are linked to the electricity market, the power generation capacity of gas-fired units increased significantly, especially scenario 1 , in which carbon prices are high.

\section{Conclusions}

The low-carbon transformation of the energy system is an inevitable choice to solve the climate problem. Many countries have established carbon markets, but the impact of carbon prices has not been fully considered in the electricity market. Based on China's carbon neutral plan and the construction of the carbon market, this paper considers the current status of the electricity market reform, and establishes a model for introducing carbon prices into the electricity market. The calculation example analysis proves that the carbon price changes the marginal cost of fossil fuels, so that units with less carbon emissions can gain a greater advantage in the power market bidding, and thus have greater benefits. It gives market players a price signal for low-carbon transition and is effective, which could promote the low-carbon transformation of the energy system.

At present, China's electricity market and carbon market are still in the construction stage. The design of the market mechanism is path-dependent. Therefore, it is recommended that the possibility of introducing carbon prices into the electricity market be fully considered before the market is fully established, so as to avoid the difficulty of subsequent revision of the rules.

\section{References}

1. Bangzhu Zhu, Liqing Huang, Lili Yuan et.al. International Review of Economics \& Finance, 67 : 163-175(2020).

2. Qiang Ji, Tongshui Xia, Fan Liu et.al. Journal of Cleaner Production, 208 : 1178-1187(2019).

3. Limpaitoon, T., Chen, Y. \& Oren, S.S. J Regul Econ 40, 237-260 (2011).

4. Steve Dahlke. Energies, MDPI, Open Access Journal, vol. 12(11), pages 1-21(2019).

5. Cullen J , Cullen J , Mansur E T . Social Science Electronic Publishing, NBER Working Paper No. w20795 (2014).

6. Dearing, Jack. Honors thesis, Duke University(2019).

7. Aatola P, Ollikainen M, Toppinen A . Biochemistry, 46(43): 52-63(2013).

8. Kim W, D, Chattopadhyay, Park J B. Energy, 35(8):3441-3448(2010).

9. Michael Goldblatt. Climate Policy, Taylor \& Francis Journals, vol. 10(5), pages 511-526(2010).

10. Easwaran Narassimhan, Kelly S. Gallagher, Stefan Koester \& Julio Rivera Alejo. Climate Policy, 18:8(2018). 